\title{
Multidimensionality of online trolling behaviors
}

Madelyn R. Sanfilippo ${ }^{1 *}$, Pnina Fichman ${ }^{2}$ and Shengnan Yang ${ }^{2}$

1. Information Law Institute

School of Law

New York University

2. Rob Kling Center for Social Informatics

Indiana University, Bloomington

*Corresponding author:

406 Wilf Hall

139 MacDougal Street

New York, NY 10012

mrs771@nyu.edu 
Multidimensionality of online trolling behaviors

\begin{abstract}
As trolling became an integral part of online communities, use of the term evolved and expanded significantly. This paper proposes a typology of trolling behaviors and compares the use of the terms troll and trolling by North American college students with scholarly and media uses. The study provides conceptual nuance based on two focus groups and four follow-up individual interviews. Participants differentiate between light-hearted trolling and anti-social trolling, which is the dominant focus of published works. The paper distinguishes between four behavioral types: serious trolling (implying that it is not funny and likely motivated by social or political ideology), humorous trolling, serious non-trolling behaviors, and humorous non-trolling behaviors. Key behavioral dimensions are identified, including: 1) pseudo-sincerity; 2) intentionality; 3) provocativeness; 4) repetition; 5) satire; 6) communicating serious opinions; and 7) representing public opinions. Formal concept analysis clarifies relationships between behavioral dimensions and types.
\end{abstract}

\title{
Keywords
}

Online trolls; online behavior; social perception; motivations; focus groups; social informatics

\section{Introduction}

Online trolling is increasingly prevalent, with abundant news media representations, yet little scholarship addresses its root causes, consequences, or social perceptions. This might be due to the fact that the meaning of "online trolling" is evolving. Online trolling has not been well defined or differentiated from other online behaviors. In addition, popular use of the words "troll" and "trolling" have varied connotations.

As trolling increased in prevalence and visibility online, use of the term broadened and diversified (Phillips 2011a). Sharp divides in stakeholder perceptions exist between perpetrators, scholars, the media, and the public at large. On one hand, actors who engage in online deviance, including trolls, often justify their behaviors ideologically or by the high moral disengagement experienced with respect to their online activities (Suler and Phillips 1998), while on the other hand, scholars and the media often frame trolling as unjustifiable and depraved acts (Bishop 2014). Recognizing trolling motivations as valid is important to social acceptance of behaviors 
MULTIDIMENSIONALITY OF TROLLING

(Postman 1953). Because ideological expression is particularly valued (Redish 1982), trolling is more accepted when perceived to be driven by ideological factors, such as free speech preferences (Fish 2016), pro-choice beliefs (Sanfilippo, Yang and Fichman 2017), or misogyny (Milner 2013). Despite suggestions that some trolls may be driven by their ideologies (Shachaf and Hara 2010), like Hacktivisits, who engage in hacking to achieve social and political goals (Coleman 2014), media depictions frame trolling as a social disease, headlined with labels such as “Trolls are jerks" (@ ThisHour 2014) and discussions of "Twitter trolls' vile threats” (Fox News 2015).

Most scholarly literature on online trolls presents the point of view of those who are impacted by trolling (e.g. Herring et al. 2002; Shachaf and Hara 2010), while little scholarly work presents trolls' points of view, with work by Phillips (e.g. Phillips 2011a; 2011b; 2011c; 2015) providing a notable exception. Victims and outside observers often perceive trolling as antisocial or deviant (e.g. Suler and Phillips 1998; Wilson, Fuller and McCrea 2013). Scholarly representations seemingly overemphasize negative aspects, ignoring the aggregate impacts of trolling or socially positive examples and the legitimate motivations of some trolls (Kirman, Lineham and Lawson 2012). One difference between scholars and the media is that scholarly narratives carefully distinguish between cyberbullying and trolling, while journalists equate the two, particularly in the context of R.I.P. pages on social media (e.g. Phillips 2011a; 2011b). Unlike other forms of online deviance like identity deception or computer mediated infidelity (e.g. Bergstom 2011; Utz 2005), trolling is often depicted as uniformly deviant, with negative consequences.

Certainly malevolent behaviors associated with trolling are deviant, yet not all trolls seek to harm. Stigmas associated with trolls seem to stem from extreme examples that have 
MULTIDIMENSIONALITY OF TROLLING

received viral attention, such as RIP trolls (Phillips 2011b), trolls race baiting in the context of the 2012 Obama campaign (Burroughs 2013), or the association of trolling with misogyny and Gamergate. Yet, without mitigating the seriousness of these cases, many who actively engage in online communities have experienced trolls who are simply annoying or humorous (Gammon 2014). Humorous trolling behaviors are common and contrast starkly with deviance. It is unlikely that a behavior that is perceived as deviant will become so prevalent and thus normative. Thus, investigation of the perceptions of trolls and trolling is particularly important, as there is a tension between common published narratives and a wider range of public perceptions.

A number of studies have been conducted over the years to better understand perceptions of specific trolling cases (e.g. Shachaf and Hara, 2010; Utz 2005), contentious online behaviors (e.g. Whitty 2005), or works on gender and context (Fichman and Sanfilippo 2015; 2016). Yet few have sought to understand either perceptions of the phenomenon as a whole or differences between published representations of trolls and public perceptions of trolling.

Some of the earliest scholarly recognition of trolling as a concept distinct from other online behaviors focused on trolling to enforce gender roles and victimize feminist spaces (Herring et al. 2002); this anti-social dimension of trolling with respect to gender has not diminished (Shaw 2013) and often is coupled with harassment (Cole 2015). Cole (2015), for example, explored violent anti-feminist rhetoric and the use of trolling to enforce patriarchical social boundaries and gendered social roles on social media. This study found continued and emboldened anti-social rhetoric targeting women, despite affordances and subcommunities supporting female response, such as \#mencallmethings and \#yesallwomen (Cole 2015). This visibility of such rhetoric and behavior by trolls not only shapes experiences with trolling in a gendered way (e.g. Phillips 2012), but is likely also associated with the overwhelming 
MULTIDIMENSIONALITY OF TROLLING

interpretation of trolling as a male activity. Fichman and Sanfilippo (2015) explicitly explored gendered perceptions of trolling, and found that male trolls were viewed more negatively, while female trolls were often interpreted as being confused, rather than actually intending to troll.

As trolling grows increasingly prevalent and manifests as disparate behaviors in disparate communities (De Seta 2013), public perceptions are likely to differ contextually. Anecdotal accounts suggest that high school and college students use the terms troll and trolling differently from the media and the scholarly literature. Given that most trolling results from the actions of teenagers and young adults, 18-34 (Gammon 2014), their understandings are likely to be based on personal experiences. Still, little is known with respect to perceptions of trolling within this group: what are college students' experiences with online trolling?; how do they understand trolling?; in what contexts do they perceive it to be most prevalent?; and what are specific relationships between experiences with and perceptions of trolling?

This study attempts to clarify trolling conceptually, by studying youth understanding. Specifically, this paper examines perceptions of trolling behaviors among college students in North America, and compares their use of the term with scholarly and media uses.

\section{Background}

Scholarly works on and definition of online trolls have evolved over time. For example, Herring et al. $(2002,375)$ include "three definitional criteria for trolls: 1. Messages from a sender who appears outwardly sincere. 2. Messages designed to attract predictable responses or flames. 3. Messages that waste a group's time by provoking futile argument." Hardaker defines a troll as "a CMC user who constructs the identity of sincerely wishing to be part of the group in question, including professing, or conveying pseudo-sincere intentions, but whose real intention(s) is/are 
MULTIDIMENSIONALITY OF TROLLING

to cause distribution and/or trigger or exacerbate conflict for the purposes of their own amusement" $(2010,237)$. Both assert that conflict is provoked through pseudo-sincere contributions, but differ in nuance within these definitions. Hardaker notes the importance of motivations and objectives in addition to intentions, behavioral tactics, and reactions. Understanding the motivations and objectives of trolls shapes perceptions of trolling behaviors (Fichman and Sanfilippo 2015). Trolls are also understood differently based on individuals' experiences in contexts, leading to a range of definitions (Phillips 2011a), and trolls have been characterized in many ways across scholarly literature, media discussions, and in general discussion (Fichman and Sanfilippo 2016).

Definitions appear to be shaped in the context of exposure, just as perception of trolls' motivations is context dependent (Fichman and Sanfilippo 2015). In fact, social context has long been established, within social informatics, as shaping outcomes, given that actors, behaviors, and technologies shape one another through interactions (e.g. Kling and Iacono 1984; Sawyer and Eschenfelder 2002). Because technologies and their users do not exist in isolation and their context, the conditions and communities surrounding them, mutually shape each other (Kling and Courtright 2003).

Likewise, understanding of trolling is likely shaped by experiences in context, as shown in recent scholarship by Phillips (2011a; 2011b; 2013) and Bishop (2014), who examine feedback loops between media and trolling in distinct cases. Phillips (2013) illustrates how misunderstandings, based on lack of experience (as in the cases of Oprah and 4chan, as well as of Fox News and Anonymous), shape trolling behaviors by drawing attention to them. The media attention provides the trolls greater platforms, and stigmatizing them in ways that support group identity formation among trolls (Phillips 2013). Furthermore, media representations of the same 
MULTIDIMENSIONALITY OF TROLLING

behavior may differ by context, as in a case prosecuted under anti-trolling legislation in the UK that dealt with racial prejudice (Bishop 2014). Aside from these feedback loops, evidence exists that experiences with trolls and trolling subreddits have greatly shaped the perceptions of and reactions to trolls for Redditors, with trolling subreddits and their members being much more accepting of trolls than those who perceive them to infiltrate non-trolling sub-communities (Bergstrom 2011).

Assuming that 1) ICT use is situated and context dependent (Kling and Iacono 1988); 2) there is social shaping of outcomes (e.g. Iacono 1996); and 3) social outcomes and identities are shaped by ICT use (e.g. Wade 2014), this paper examines, through a social informatics lens, the specific propositions emerging from the literature associated with multidimensionality of trolling. First, perceptions of trolling vary by context because communities and individuals have different experiences with trolling. Second, trolling behaviors are inconsistent from community to community, because unique contexts have evolved over time, through different social expectations, including triggers and opportunities for trolling, and different configurations, including technical and policy factors that may enable trolling. Third, following a transitive logic, perceptions of the same behaviors across contexts and application of the term differ based on the evolution of trolling behaviors within distinct communities, as well as based on the extent of overlap or influence from community to community. This study aims to provide a better understanding of the range and nature of trolling, examining these propositions, from the view of college students in North America, an important and understudied population with respect to this topic.

\section{Methods}


MULTIDIMENSIONALITY OF TROLLING

Data were collected through 2 focus groups and 4 individual semi structured interviews, ranging from 30 minutes to 1 hour and 30 minutes in May-June 2015, from 10 participants. Students from a large public university in North America were recruited through listservs and social media. Majority of the participants were undergraduate $(n=7)$, male $(n=8)$ students and they had diverse academic backgrounds, including biology, business, computer science, informatics, and library science. Furthermore, participants included international students $(n=2)$ from China and South Korea, as well as domestic US students from the Midwest $(n=5)$, Northeast $(n=1)$, and South $(n=2)$, and diverse ethnic backgrounds, though these distributions are not representative. Their primary online communities of interest ranged from specific online games to game streaming, sports forums to photo-sharing communities, fandoms to political or humor blogs, and Twitter, reflecting the multifaceted opportunities afforded for specificity of interests online, though many participants discussed experiences in multiple communities.

Focus groups were designed to provide a relaxed environment in which participants would be comfortable discussing experiences surrounding trolls and trolling. Follow-up questioning and four one-on-one interviews allowed self-selected participants to describe anecdotal experiences with trolling. These semi-structured interviews aimed to expand focus group discussions, beyond topics of questions, to allow for participants to share more information from perspectives of having trolled, observed trolling, and being trolled. Focus groups methodologically supported assessment of social perception because students were able to negotiate their opinions and bounce ideas off of one another, which allowed for rich data collection (Wilkinson 1998). Focus groups consisted of three distinct parts that were audio recorded and transcribed later.

First, all participants were asked some form of the following semi-structured questions: 
MULTIDIMENSIONALITY OF TROLLING

1. How would you explain what a troll is to someone who didn't know?

2. How do you identify a troll online?

3. What do you think counts as trolling?

4. Do you ever disagree when someone calls something trolling? If so, what do other people call trolling that you would not?

5. How are trolls different than hackers? Cyberbullies? Are there any similarities between trolls, hackers, cyberbullies, or other deviants in terms of motivation? Do you think that trolls would ever engage in these other behaviors or that people who engage in one type of online deviance would be more likely to engage in another?

6. Why do you think trolls behave in the ways that they do?

7. Do you think that ideology motivates trolls? Politics? Curiosity? Instigation? Humor? Confusion? Malevolence? Loneliness? Technology? Psychology?

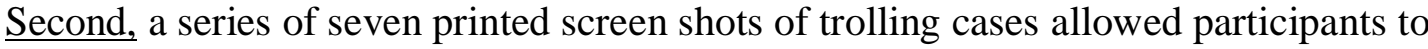
differentiate their perceptions of trolling from media and scholarly interpretations of the events. Cases were selected as instances of trolling based on their identification either by participants in an online community or by outside observers. Cases reflected diverse behavioral tacticsincluding memes, sarcasm, direct provocation, and textual vandalism—and spanned multiple platforms — including discussion forums, social media, Wikipedia, and chat rooms.

$\underline{\text { Third, }}$, open discussion of personal experiences with trolling was facilitated. Participants were asked to reflect on the specific roles they had played with respect to trolling, including as trolls, targets, observers, or administrators. Questions were tailored to their experiences, about the communities in which they most often played these roles and witnessed or experienced 
MULTIDIMENSIONALITY OF TROLLING

trolling. Participants were also asked to reflect also on the behaviors and experiences of friends and family with trolling.

Audio recordings were transcribed and analyzed using NVivo, software for qualitative data analysis. A codebook was designed for the categorization and conceptualization of the data (Bendassolli 2013). The initial codebook was based on the literature; new codes were added gradually to reflect features and characteristics of trolling as additional interview data were collected and transcribed. The final codebook is presented in the appendix. All identities of participants have been anonymized through the use of persistent alphabetic pseudonyms; references to participants' online identities were removed from transcripts.

Two coders, one of whom also collected data and developed the initial codebook, engaged in an iterative process of redefinition and recoding until consensus, with agreement over 95\% for all codes, was reached using one focus group. Cohen's kappa coefficients for all terms measured between 0.81 to 1 , which implied IRR approached perfect agreement. The unit of analysis was an individual's entire response. At times it was necessary to maintain the coherence within context and dialogue between interviewer(s) and respondent(s), or several successive posts were coded continuously. For each post, there was no limit to the number of codes that could be applied and codes were also applied multiple times within the same conversation. Coding of subsequent transcripts only commenced once the codebook was finalized.

In addition to the coding, relationships based on concepts identified and distinctions made by participants were analyzed through formal concept analysis (FCA). Through FCA, mathematical lattices are constructed based on the data in order to represent conceptual structure and interconnectedness and graphs demonstrating hierarchies are produced (Priss 2006; Hara 2002). Concept Explorer (https://sourceforge.net/projects/conexp/) and LucidChart 
MULTIDIMENSIONALITY OF TROLLING

(https://www.lucidchart.com) were employed. FCA was based on concepts in participant responses to cases; the non-static graphs produced, were transformed into non-weighted visualized models, so as not to claim quantitative significance, given the small sample size of ten participants.

Among the limitations of the study is the small sample and the potential for groupthink within focus groups, which preclude claims of generalizability. Yet the constraints imposed by this design were intentional, as tradeoffs associated with both small samples and focus groups supported the exploratory nature of this inquiry. Research in social methods has explored the value of sample sizes smaller than $N=20$ for interview based work, determining that deep analysis of rich description is useful for preliminary work (Crouch and McKenzie 2006). In order to identify concepts for exploration in future work, it was necessary to use a small sample to actually capitalize on data richness, rather than seeking patterns that may or may not be generalizable from a more moderate sample (Crouch and McKenzie 2006). Thus, transferability of findings should be made with caution.

Focus groups are often treated skeptically is that respondents may coalesce around arguments, rather than sharing diverse opinions, thereby biasing data (Wilkinson 1998). In this case, the interest in social perception, rather than individual's perceptions, and the supplemental design to include follow-up interviews, when appropriate, minimizes these risks. An advantage of combining content analysis and concept analysis in this study is to reveal the level of consensus among study participants and to emphasize both compelling explanations and relationships. Active moderation in this study supported contribution of ideas from all members of each focus group. The words contributed per participant ranged from 1833 to 2668 in one focus group (45 minutes) and from 7614 to 9512 in the other (1 hour and 30 minutes), illustrating 
MULTIDIMENSIONALITY OF TROLLING

that more dominant participants did not silence others and all were able to contribute substantively. It is important that future research examine issues of race, ethnicity, and gender, with respect to trolling, as they are central to issues of identity for trolls (Fichman and Sanfilippo 2015; Gray 2014; Milner 2013; Williams, Oliver, Aumer and Meyers 2016).

\section{Results and Discussion}

Frequencies of codes are summarized in Table 1 and results are discussed in three sections: 4.1) qualitative analysis of participant experiences; 4.2) conceptual analysis, supported by formal concept analysis; and 4.3) discussion of a proposed typology of trolling along two axes, humor and social inclusivity.

\subsection{Perspectives on Trolling}

\subsubsection{Experiences with Trolling}

Establishing participants' experiences with trolling provides an initial understanding of how their interactions with trolling may have shaped their perceptions of these behaviors. Section 4.1.1.1 illustrates how differences in experiences exist across the three roles: the observer or bystander, the troll, and the target or victim; section 4.1.1.2 illustrates how context creates diversity of experiences.

\subsubsection{Roles and experience:}

Participants argued that differences in roles and experiences shape different opinions about trolling. Participant G, for example, differentiated between roles, articulating variation in experiences with trolling: "from being on all three sides, you know, the trolling, the being trolled, and the observing of the trolling." Observation is particularly important because indirect 
MULTIDIMENSIONALITY OF TROLLING

roles, as bystanders or enablers, also shape understanding of trolling, particularly for those who don't have experience in the other roles.

There was a pervasive sentiment among participants that the media and scholars take trolling too seriously and look at extreme cases, reflecting an entirely different online experience than that of the youth. Generational differences were explicitly identified as a reason for different opinions, reflecting various social expectations and life experiences. Specifically, college students and adult professionals, as well as teenagers and the elderly differ from each other. The gendered nature of experience, as well as of contexts, was also recognized by participants as important to perceptions and behaviors, mentioned relative to trolling and discrimination in online gaming, including with respect to \#GamerGate. This is consistent with previous analysis of gender and trolling (e.g. Fichman and Sanfilippo 2015; Herring et al. 2002; Shaw 2013). Participants also claimed that context impacts their perception of whether the behavior is trolling or not. Drawing on experiences, they explained how they have seen standards, expectations, and norms of behaviors formed through participation; norms define deviant and normative trolling behaviors for the community and establish roles in interactions.

\section{The observer role (the bystander):}

Observers' opinions are context dependent and unique to specific platform or community. Observers who have experiences with trolling are able to identify trolling behaviors more easily, because understanding of expectations requires embeddedness in the community. One participant explicitly stated that they didn't find trolling pleasurable, but did enjoy observation of trolls and others' encounters with them. Many participants affirmed that they found enjoyment in passive consumption of trolling more than in active trolling behaviors; one explained that they rarely 
MULTIDIMENSIONALITY OF TROLLING

actively engage, but rather enjoy the passive observer role as entertainment and a way to stave off boredom.

\section{The victim role (the trolled):}

Participants spoke about their experiences being trolled. For example, participant I compared and contrasted the experience of being trolled to being targeted by a playground bully as a child; both experiences were construed as negative, but part of growing up. Participants saw similarity in that retaliation often leads to being targeted further and is only worthwhile when one knows they can one-up the troll or bully, thereby diminishing their power. Unlike trolling, which often targets the inexperienced, bullying more often draws on personal information in known interaction. However, an exception to the impersonal nature of trolling is the targeting of victims by gender. Participant I emphasized the importance of maintaining ambiguous personas online to evade trolls' interest, as a lesson learned, advising others specifically not to mention “gender because that's the very first thing a troll goes after if you're a girl, like oh you're a chick, you know, the usual GTFO sort of thing".

A very different example of being targeted is in a group that reflexively trolled one another; they used their experience being targeted as impetus to target and troll their friends. Participant F described casual group trolling simply as "laughing with your friends and like playing a joke. That's kind of a lot of the motivation..." Discussions illustrate that not all of those who are trolled have similar experiences and even those who are targeted can accept lighthearted trolling.

\section{The casual troll role:}

While various participants spoke of occasional and light-hearted trolling experiences, only one described their own iterated, committed participation in a specific form of trolling. This 
MULTIDIMENSIONALITY OF TROLLING

participant was an active gamer who regularly coordinated with large groups, including thousands of concurrent viewers, to troll streamers via Twitches.

However, multiple participants engaged in casual trolling, which provided a distinctly different perspective on the phenomena. They discussed their experiences trolling with a group as being particularly formative experiences. For some participants, group trolling was what they were comfortable sharing, though some acknowledged other experiences, while others only found trolling in groups to be enjoyable. One participant explained that they believed sporadic trolling within a group of friends was acceptable, but that they saw a stigma to trolling alone and this prevented them from engaging in the behavior in other contexts.

\subsubsection{Context and experience:}

Beside the role of participants, observers, victims, or active trolls, the context in which trolling was experienced was perceived to be important. Participants affirmed similarities between trolls and trolling associated with 4chan and Reddit, yet perceived that to be quite distinct from Facebook or small online communities. Participants indicated that behaviors often differed from community to community, sometimes because platforms or communities enable trolling, yet, some engage in trolling on multiple platforms. One participant contrasted their experiences across Twitter, Facebook, X-Box Live, and PS3, explaining that single users often trolled from place to place, but that manifested in different behaviors in different communities. Another participant went on to explain that different behaviors from different users, both trolls and the trolled, would vary due to contextual differences in expectations.

Personal experiences, across roles and contexts, shape participants' perceptions of trolling more than common narratives or efforts at social construction of the concept by scholars and media. To illustrate how often personal experience was invoked in explanations of the 
MULTIDIMENSIONALITY OF TROLLING

various concepts, the instances in which each code co-occurs with the code for personal “experience" are presented in Table 1 as a percentage of each code's frequency. With respect to experience, participants' roles and the context of trolling were critical lenses through which perceptions of trolling were formed. Experiences allow users to identify, respond to, and classify different behaviors as trolling, yet common and mainstream experiences lead to similar impressions, at least within social and demographic groups.

\subsubsection{Types of Trolling Behaviors}

Participants emphasized that different types of trolling co-exist in online communities, arguing that not all trolling alike. Two types of trolling behaviors emerged; one that is negative and deviant, similar to the common narrative in the media, and another that is normative, humorous and prevalent within online communities. Participants drew on their experiences to validate and justify their perceptions of trolls and trolling, in ways that contrasted from previous scholarly representations and media perspectives. Their perceptions of trolling were overwhelmingly more positive than the common scholarly narrative and more light-hearted than the media depictions. These different depictions may be due to the fact that participants more sharply differentiated between trolling and behaviors like cyberbullying. In this section, through comparison of discussions with existing scholarly and media depictions, the two behavioral trolling types that emerged will be highlighted.

While participants also shared negative perceptions of trolling, consistent with media and scholarly analyses, trolling was not always viewed as anti-social or deviant from the perspectives of college students. They differentiated between types of trolling based on whether it is intended to elicit humor or negative responses, yet still suggested commonalities. For example, participants agreed that trolling is always provocative in nature. They emphasized that trolling is 
MULTIDIMENSIONALITY OF TROLLING

designed "to invoke a reaction" (Participant A), or, when less thoughtfully constructed, "prodding for reaction" (Participant E). Many explicitly employed the terms "reaction" (e.g. Participant F) or "provoking" (Participant H) in their personal definitions, while others cite specific reactions, such as anger (e.g. Participant J).

Participants used examples of behavioral tactics to describe trolling, indicating that trolls are best understood by their behaviors. These tactics are consistent with the scholarly literature, in which behavioral dimensions in context are argued to better identify and explain trolling than motivations for, reactions to, or impacts of trolling (e.g. Phillips 2011b; 2011c; Karppi 2013; Shachaf and Hara 2010). Providing resistance to individual and group perspectives, by “intentionally disagreeing” (Participant C) or "taking the opposite stance” (Participant B), trolling is fundamentally provocative.

Participants also identified distinct tactics with respect to light-hearted versus malevolent trolling. Specifically, motivations to seek enjoyment lead trolls to find humor in disruption and disagreement, because they enjoy getting a rise out of people. In contrast, other behaviors "mock or basically degrade" (Participant H) individuals online because they are "messing with people, making people angry" (Participant J) or hoping to "bring riot" (Participant F). In other words, the extreme side of the spectrum includes more malevolent or anti-social behaviors, resembling the depiction of trolls in the literature; participants made it clear that trolling is typically about humor and entertainment, in their experiences.

Participants argued that confusion about normative humorous trolling and deviant malevolent trolling, as well as lack of experience with trolling, lead to misapplication of the terms troll and trolling, which further increases confusion. They argued that the term is becoming less meaningful; it extends beyond disagreement in application, to also include the use of trolling 
MULTIDIMENSIONALITY OF TROLLING

as an excuse for more anti-social behaviors. There were, however identified misperceptions of trolling, including that sarcastic comments on Facebook or YouTube or fake posts or profiles are automatically identified as trolling, rather than sarcasm or identity deception that might be involved with trolling.

In summary, personal experiences with specific communities, as well as with trolls and trolling in different roles, shape participants' perceptions of trolling. Social narratives are insufficient to define and understand the behavior; personal interactions are as important. Validity and accuracy of interpretations is also judged by these participants, on the basis that those who lack experience yet hold strong opinions and indiscriminately apply the label "troll" to online actors without contextual understanding propagate confusion. It is from these experiences that participants differentiate between hard-core or malevolent trolls, at the center of published research and media depictions of trolling, and light trolling, which seems to capture much of the attention study participants. Light-hearted behaviors, which are non-malicious, can be either humorous or serious. As not all serious or humorous behaviors can be characterized as trolling, four distinct behavioral types emerged:

1) serious trolling (implying that it is not funny and likely social or political motivated);

2) humorous trolling;

3) serious non-trolling behaviors; and

4) humorous non-trolling behaviors.

Characterization of these behavioral types was developed systematically through FCA and is presented in section 4.2.2.

\subsubsection{Behavioral dimensions of trolling}


MULTIDIMENSIONALITY OF TROLLING

Most participants discussed seven distinct dimensions (Table 2) when differentiating trolling from other behaviors and interactions online. These dimensions included whether behaviors:

1) communicated serious opinions;

2) were representative of public opinions;

3) were pseudo-sincere;

4) were intentional;

5) were provocative;

6) repeated; or

7) were satirical.

It is important to note, that while questions were asked about other behavioral dimensions, most participants were only concerned with these seven, which are defined in table 3. Clear consensus that distinct concepts were central to evaluation of trolling is represented by $90-100$ percent of the participants invoking the dimension or motivation in their analysis. Participants largely ignored other dimensions that appeared in published works. For example, they were not concerned about: a specific target or target group, whether interaction was one to one or one to many, modalities, or the nature of the platform. This pattern of emphasizing only a subset of characteristics from those emphasized in the literature was mimicked with respect to motivations to troll. Enjoyment, ideology or politics, and social factors were emphasized, but participants disregarded technological, psychological, or other motivations when questioned.

\section{$\underline{4.2}$ Formal Concept Analysis}

In an effort to better understand shared perceptions and to identify the relationships between multiple trolling behaviors, explored participant responses were explored through formal concept analysis (FCA). Specifically, relationships were explored between the four behavioral types and 
MULTIDIMENSIONALITY OF TROLLING

the seven behavioral dimensions, as well as trolling motivations, in three stages. In section 4.2.1, cooccurance of multiple behavioral dimensions creates specific multidimensional behaviors. In section 4.2.2, correlation between multidimensional trolling behaviors and the four behavioral trolling types are explained. In section 4.2.3, relationships between motivations and the four behavioral trolling types are explored.

\subsubsection{Multidimensional Behaviors}

Concept analysis suggests, based on frequency of co-occurrence and relative participant consensus, that the conclusions are likely given a case of trolling in which the premises enumerated are true (table 4). Given the small sample size that generated these results, order of prevalence may not be generalizable and causality cannot be discussed. However, relationships between premise and conclusion are likely and can be directional or bidirectional; directionality would indicate either that the conclusions are dependent (directional) on or independent (bidirectional) from but it is associated with premises regardless. Directionality is identified based upon statistical independence and correlation. For example, the first row in Table 4 means: 1) if a trolling behavior is provocative and satirical, it is also likely to be repetitive; and 2) if trolling behavior is repetitive, it is more likely to be provocative and satirical. Correlations that cluster certain behavioral dimensions identify possible predictive relationships that can be tested. For example, looking at the third row, it can be expected that behaviors that are pseudo-sincere and communicate serious opinions, are deliberate or intentional, and employ satire to communicate those opinions. However, the directionality is logical in that not all satirical behaviors are trolling, even when satire is coincidental with intention and serious opinions.

Additional simple patterns of co-occurrence of behavioral dimensions imply high likelihood of other specific dimensions. For example, serious opinions and satire, when co- 
MULTIDIMENSIONALITY OF TROLLING

occurring, also co-occur with pseudo-sincerity and intentionality. Furthermore, the co-occurrence of serious opinions and intentionality might predict pseudo-sincere satire. Pseudo-sincerity, serious opinions, satire, and intentionality almost always co-occur as trolling behavioral dimensions. However, certain combinations of dimensions are more likely to co-occur and these combinations allow for the prediction of other applicable dimensions. Despite the complexity of this example, there are other clusters that have simple implications from co-occurrence. For example, if a behavior includes all of the following dimensions: serious opinions, repetition, pseudo-sincerity, intentionality, provocative, and satire; it is also likely representative of public opinion, as can be seen in row 9. However, this is only likely to happen in instances of serious trolling and not in instances of humorous trolling or non-trolling behaviors, because of associations between behavioral dimensions and the four behavioral types, which are illustrated in Figure 1. Similarly, if a behavior includes the dimensions of serious opinions, representative of public opinions, repetition, provocative, and satire, it is also likely pseudo-sincere and intentional, as can be seen in row 11. This is only likely to occur in cases of serious trolling, when trolls are motivated by ideological or social factors.

There are also a number of complex clusters that predict other multidimensional clusters, indicating commonalities between combinations. For example, if repetition, intentionality, provocative, and satire are all dimensions of a behavior, it is likely that the behavior also incorporates serious opinions, is representative of public opinions and is pseudo-sincere (Table 4, Row 4). Furthermore, if serious opinions, repetition, provocation, and satire are all dimensions of a behavior, it is likely that the cluster of dimensions including representativeness of public opinion, pseudo-sincerity, and intentionality are also dimensions of the behavior as can be seen in row 8. 
MULTIDIMENSIONALITY OF TROLLING

\subsubsection{Dimensions of Behavioral Types}

The patterns of co-occurrences allow for differentiation between 1) trolling and nontrolling behaviors, and 2) humorous and serious behaviors (Figure 1). The relationships between the seven behavioral dimensions and the four behavioral types are represented in a model (Figure 1). It is clear that there are fewer patterns of co-occurrences associated with humorous trolling then with serious trolling. One specific dimension, pseudo-sincerity, is associated only with trolling. This suggests that if a behavior is pseudo-sincere, it is trolling. This can be explained because the cluster of conclusions around pseudo-sincere behaviors are all characteristic of deliberate farce. It is possible that the mocking nature of satire is most successful when delivered as an extreme perspective.

Figure 1 also illustrates differences between serious and humorous behavioral types. Serious non-trolling behaviors were the only identified to be representative of public opinion. Intentionality, can be used to differentiate humorous trolling and non-trolling. Humorous behaviors, trolling and non-trolling, can be differentiated by intentionality. Humor that is not bound in trolling behaviors is sometimes unintentional. Trolling also often incorporates satire, which resembles serious trolling. The primary distinctions between serious and humorous behaviors include incorporation of opinions and whether or not there were repeated actions.

The difference between serious, provocative trolling and non-trolling lies in whether it is representative of public opinion. While both of these multidimensional behaviors are always intentional, they differ in how far they lie from social norms of acceptability. Both serious trolling and non-trolling are provocative, as are humorous trolling and non-trolling, indicating that it is impossible to identify trolling based on the degree to which it is provocative or humorous. Serious trolling is more light-hearted than malevolent, revealing a heuristic employed 
MULTIDIMENSIONALITY OF TROLLING

to differentiate between actual extremism, as a form of serious non-trolling, and satire of extremism, as a manifestation of serious trolling.

Based on this analysis we can define each of these behavioral types:

1) Serious trolling is defined as intentionally provocative and pseudo-sincere behaviors that reflect serious opinions and values.

2) Serious non-trolling includes sincere behaviors intentionally reflecting public opinions and can be interpreted prima facie.

3) Humorous trolling is defined as intentionally provocative and repetitive behaviors motivated by personal or social enjoyment or entertainment. Humorous trolls are more effective when pushing the boundaries of social acceptability, rather than reflecting extreme opinions (Goel and Nolan 2007; Kirman, Lineham and Lawson 2012).

4) Humorous non-trolling is also repetitive, satirical, and often provocative, yet distinct from trolling behaviors in that it is not pseudo-sincere. Humorous non-trolling encompasses a wide variety of behaviors and rhetoric.

It is clear that behavioral dimensions often employed in scholarly definitions of trolling, such as repetition and provocation, are associated both with trolling and with non-trolling behaviors. This may explain frequent misapplications. It is notable that participants did not consider anonymity significant to trolling and did not consider a provocative nature to be sufficient in identifying trolling. While pseudo-sincerity could be used to identify trolling behaviors, all participants considered trolling to be multidimensional and context dependent. This also supports adopting a social informatics perspective in seeking to understand this online behavior.

\subsubsection{Motivations for Behavioral Types}


MULTIDIMENSIONALITY OF TROLLING

Relationships between motivations and the four behavioral types are complex. For example, both non-trolling behaviors can be motivated by ideological and/or political factors, yet characterization as serious does not co-occur with enjoyment as a motivating factor, and serious trolling does not co-occur with social motivators. While the former is intuitive, the latter ought to be further explored. Trolling is often explained to be a way to express serious opinions in a way that garners attention and is not abrasive, but it is possible that this narrative does not coincide with perceptions. An alternate explanation that better fits perceptions, as documented in this study, would be that trolling supports expression of serious opinions because of emotional affordances, rather than social benefits. The implication being that people engage in serious trolling because it is a more appropriate form of expression for themselves, not because it will be viewed as more acceptable than serious non-trolling.

There are also complex differences between humorous trolling and non-trolling. Specifically, while humorous trolling is motivated by enjoyment, social factors, or a combination thereof, humorous non-trolling is either motivated by one or the other, and not by a combination of the two. It is understandable that humor can serve a purpose of group bonding, as easily as it can entertain an individual. Trolling is perceived to be a way to satisfy both social and personal enjoyment needs, likely because of forms of trolling that are recognizable and allow for others to join in, while still entertaining the individual. Behaviors like rick-rolling, or other instances of trolling that reference shared experiences or popular culture, leverage this in a way that humor independently does not. There is also evidence that combining humor with other motivations leads to trolling.

In summary, FCA supports differentiation between humorous and serious trolling and non-trolling, yet many behavioral dimensions co-occur across types, producing patterns that 
MULTIDIMENSIONALITY OF TROLLING

explain the challenges of identifying and reacting to trolling behaviors. Trolling motivations complicate this further, as some are common, like enjoyment, and others help differentiation, as with social motives between humorous and serious trolling. The overall significance lies in that a multidimensional conceptualization of trolling is necessary to identify and explain trolling.

\subsection{Typology of trolling: Humor and social inclusivity}

Trolling behaviors are more complex and diverse than dominant scholarly and media narratives often recognize. There is recognition among college students that differences in perceptions between stakeholder groups, are products of the sociotechnical nature of experienced interactions between trolls, other individuals, and online communities. Figure 2 illustrates a comparison between perceptions and the behavioral types they emphasize. A more nuanced view of trolling, based on a social informatics perspective that assumes context and experience lead to differences in outcomes, behaviors, and perceptions, is useful in discussing these findings.

This specifically leads to the conclusion that college students' perceptions differ from other demographic groups, such as older generations, as well as from those in distinctly different stakeholder groups, such as the media and scholars, based on their different experiences. Variation within college students' experiences likely also occurs, due to socioeconomic and cultural differences (Gray 2014; Milner 2013). The media focuses on negative aspects of trolling (Bishop 2014) and this tendency conflicted with participants' experiences and perceptions.

Scholars focus on more negative online behaviors or instances in which they were targeted (e.g. Herring et al. 2002). Older generations participate less intensively in online communities and are less likely to participate at all in communities where trolling is most prevalent, such as gaming communities (Gammon 2014). 
MULTIDIMENSIONALITY OF TROLLING

In contrast, college students are more aware of the nuances of trolling because of their online experiences. When discussing what counts as trolling, one participant offered Justice Stewart's "I know it when I see it", justifying their ability to identify trolling based on their having grown up with the Internet. Participants also had earlier experiences with trolling and many associated trolling behaviors with exploration in their younger years. Many of them trolled in high school and found more humor in it.

Previous literature and media treatment of trolling conflated trolls and trolling. However, participants distinguished between the two and argued that not everyone who engages in the behavior is, in fact, a troll. Some argued some people find humor in it and occasionally troll, but are not trolls. Others emphasized that trolls are committed and iterate their behaviors, while trolling is circumstantial and often one-off in nature. In line with the common scholarly narrative, trolls practice iterated behaviors, compulsion and mean-spirited trolling, whereas Participant D strongly asserted, "trolling is for everyone." The more playful forms of trolling are easily accessible for the majority of people, yet irritating or harmful forms of trolling are less accessible.

This study provides evidence that there is a difference between trolling and being a troll, as well as mean-spirited and light-hearted trolling. These two types of trolls were discussed by participants in depth, with particular emphasis on the degree to which trolls are anti-social or undesirable, while trolling is generally humorous, socially accessible, and common. Understanding the distinction, which is associated with social dynamics and motivations, is important to design and implement appropriate responses to trolls and trolling. Uniform treatment of trolling will not be effective in mitigating the impact of harmful trolls, and will diminish the socially-positive impacts of light-hearted trolling. Distinctions between trolls, 
MULTIDIMENSIONALITY OF TROLLING

trolling, and trolling-light or light-hearted trolling are presented in Figure 3. The two social dimensions that differentiated between these trolling behaviors, humor and social inclusivity, relate to social boundaries, belongingness, and enjoyment (Kirman, Lineham and Lawson 2012; Phillips 2015). Within specific contexts, there are norms about participation and communication and trolling pushes against them (Kirman, Lineham and Lawson 2012). These participants suggest that trolling pushes social boundaries and norms, sometimes lightly and sometimes too far, and perceived motivations often delineate between what is acceptable and what is not.

Beyond these distinctions, behavioral dimensions emerged in clusters further differentiating between trolling behaviors. Evidence emerged that inexperience within the community or context can lead to misidentification of behaviors as trolling, as well as misunderstandings about what dimensions of behaviors actually constitute trolling. For example, the idea that all provocative online behaviors are instances of trolling is contradicted by the experiences and perceptions of participants. In contrast, pseudo-sincerity is fundamentally identified as important; yet trolling is considerably more complex than pseudo-sincere computer mediated communication. All trolling behaviors are multi-dimensional, differing by context, and thus complex.

Motivations are also related to the public's complex characterizations of trolling, underlying the range of perceptions. There is evidence that trolling is often motivated by multiple factors, even when it is light-hearted, in contrast to humorous non-trolling behaviors, which are seen to be motivated by either enjoyment or social concerns, but not both. This speaks further to the need to understand trolling as complex, rather than reducible to a simple definition. The multidimensionality of trolling, including diversity of behaviors and experiences with them, is significant for a variety of reasons, including: diverse behaviors require diverse management 
MULTIDIMENSIONALITY OF TROLLING

and response strategies (Sanfilippo, Yang and Fichman 2017), efforts to educate children and users about online etiquette and anti-social behaviors benefit from conceptual clarity (Preece 2004), and relationships between diverse behaviors and motivations have important implications for cyber-psychology (Caspi and Gorsky 2006).

\section{Conclusions}

Perceptions of trolling reflect experiences in different contexts in roles from observers, victims, or trolls. This study, which specifically sought to understand the perceptions of college students, provides support for the relative acceptance of trolling among these participants in online communities, as well as for the assertions that trolling ranges from deviant to normative activity. College students expressed that interests in social experimentation, often associated with boredom and bonding with friends, drove recreational trolling, most commonly in adolescence. Their online experiences and recognition of behavioral diversity and distinctions between trolling and bullying provided a different perspective from other generations and user groups, such as scholars or journalists. Recognition of multiple dimensions of trolling strongly related to contextual and perspective aspects of experiences.

While there are limitations to drawing strong specific conclusions about motivations for or specific dimensions of trolling because of the small sample size considered, the richness of responses supported expansion of conceptualization of trolling. Specifically, implications of this research include: 1) distinction between trolls and trolling; 2) distinction between malevolent trolling and light-hearted trolling, which is considered to be more prevalent; 3) distinction of trolling along social and humorous dimensions; 4) the identification of four suggested behavioral trolling types; and 5) multidimensionality of trolling behaviors. 
MULTIDIMENSIONALITY OF TROLLING

With respect to the first three implications, this study organizes, captures, and analyzes public sentiments and supports emerging themes from the existing body of literature.

Specifically, serious political statements communicated through trolling (e.g. Burroughs 2013) and humorous, non-targeted trolling behaviors (e.g. Karppi 2013) have both been studied independently, yet our study adds explicit comparisons of these diverse behaviors. Likewise, based on participants nuanced insights, our study look at deviant and light hearted trolling. Whereas much of the scholarly literature focused on trolling associated with harassment (e.g. Shaw 2013), the increasingly mainstream nature of trolling and mass trolling memes have received less scholarly attention (e.g. Milner 2013).

Furthermore, the behavioral dimensions associated with trolling behavioral types can be used to differentiate between humorous trolling and humorous non-trolling. The four behavioral types further delineate between the serious and the humorous, trolling and non-trolling and illustrate why contested interpretations may occur. A specific example is provided by the difficulty that arises in differentiating between extremism and satire of extremism (Milner 2013), which constitute serious non-trolling and serious trolling, respectively, and can be more clearly identified using our typology. Similarly, issues around the personal and experiential nature of impressions of satire and humor have been discussed (Goel and Nolan 2007), but previously have not been conceptualized with respect to trolling.

Finally, this exploratory work propose that trolling behaviors are multidimensional to address contradictions in the literature as some of the dimensions considered by other scholars to be either necessary or sufficient to trolling do not reflect participants' experiences. For example, participants' resistance to identifying trolling based upon provocation contrasts between the views of college students and definitions by Hardaker (2010) and Herring (Herring et al. 2002). 
MULTIDIMENSIONALITY OF TROLLING

However, pseudo-sincerity is critical in describing trolling behaviors among participants and within the literature (e.g. Hardaker 2010).

Given the diversity of multidimensional trolling behaviors, it is also important to further differentiate between subtypes of trolling behaviors. Of particular interest is normative trolling; political trolling and humorous trolling are highly visible and under-studied. Future research should continue to explore perceptions of trolling from different social groups, as well as how experiences with trolling differ across demographic groups and contexts.

\section{References}

@ThisHour. 2014. Study: Internet Trolls are Jerks. [video]. CNN, March, 16, 2014. http://www.cnn.com/videos/tech/2014/02/19/ath-internet-trolling-freespeech.cnn/video/playlists/cyberbullying/

Bendassolli, P. F. 2013. Theory building in qualitative research: reconsidering the problem of induction. In Forum Qualitative Sozialforschung/Forum: Qualitative Social Research Vol. 14.

Bergstrom, K. 2011. "Don't feed the troll": Shutting down debate about community expectations on Reddit. com. First Monday 16(8).

Bishop, J. 2014. Representations of 'trolls' in mass media communication: a review of mediatexts and moral panics relating to 'internet trolling'. International Journal Of Web Based Communities 10(1):7-24.

Burroughs, B. 2013. Obama Trolling: Memes, Salutes and an Agonistic Politics in the 2012 Presidential Election. The Fibreculture Journal 22(2013): Trolls and The Negative Space of the Internet. 
MULTIDIMENSIONALITY OF TROLLING

Caspi, A. and P. Gorsky. 2006. Online deception: Prevalence, motivation, and emotion. CyberPsychology and Behavior 9(1):54-59.

Cole, K. K. 2015. "It's Like She's Eager to be Verbally Abused”: Twitter, Trolls, and (En) Gendering Disciplinary Rhetoric. Feminist Media Studies 15(2):356-358.

Coleman, G. 2014. Hacker, hoaxer, whistleblower, spy: The many faces of Anonymous. Verso Books.

Crouch, M. and H. McKenzie. 2006. The logic of small samples in interview-based qualitative research. Social Science Information, 45(4), 483-499.

de Seta, G. 2013. Spraying, fishing, looking for trouble: The Chinese Internet and a critical perspective on the concept of trolling. The Fibreculture Journal 22(2013): Trolls and The Negative Space of the Internet.

Fichman, P. and M. R. Sanfilippo. 2015. The Bad Boys and Girls of Cyberspace: How Gender and Context Impact Perception of and Reaction to Trolling. Social Science Computer Review 33(2).

Fichman, P. and M. R. Sanfilippo. 2016. Online Trolling and Its Perpetrators: Under the Cyberbridge. Rowman and Littlefield Publishers.

Fish, A. R. 2016. Mirroring the videos of Anonymous: cloud activism, living networks, and political mimesis. The Fibreculture Journal 26(2016):85-107.

Fox News. 2015. 'It's not the Internet's Fault': Schilling on Twitter Trolls' Vile Threats to His Daughter. Fox News Insider, March 6, 2015. http://insider.foxnews.com/2015/03/06/itspeople-not-internet-schilling-twitter-trolls-vile-threats-his-daughter

Gammon, A. 2014. Over a quarter of Americans have made malicious online comments. YouGov, October 20, 2014. 
MULTIDIMENSIONALITY OF TROLLING

Goel, V. and R. J. Dolan. 2007. Social regulation of affective experience of humor. Journal of Cognitive Neuroscience 19(9):1574-1580.

Gray, K. L. 2014. Race, gender, and deviance in Xbox live: Theoretical perspectives from the virtual margins. Routledge.

Hardaker, C. 2010. Trolling in asynchronous computer-mediated communication: From user discussions to academic definitions. Journal Of Politeness Research-Language Behaviour Culture 6(2):215-242.

Herring, S., Job-Sluder, K., Scheckler, R. and S. Barab. 2002. Searching for safety online: Managing "trolling" in a feminist forum. Information Society 18(5):371-384.

Hopkinson, C. 2013. Trolling in online discussions: From provocation to community-building. Brno Studies In English, 39(1), 5-25. doi:10.5817/BSE2013-1-1

Iacono, C. 1996. The Demise of Meaning-Making and Social Agency as Critical Concepts in the Rhetoric of an Information Age. Information Society 12(4):449.

Karppi, T. 2013. 'Change name to No One. Like people's status': Facebook trolling and managing online personas. The Fibreculture Journal: Digital Media and Networks and Transdisciplinary Critique 22(166).

Kirman, B., Lineham, C., and S. Lawson. 2012. Exploring mischief and mayhem in social computing or: how we learned to stop worrying and love the trolls. In Proceedings of the 2012 ACM Annual Conference on Human Factors in Computing Systems Extended Abstracts (CHI EA '12).

Kling, R. and C. Courtright. 2003. Group behavior and learning in electronic forums: A sociotechnical approach. The Information Society 19(3):221-235. 


\section{MULTIDIMENSIONALITY OF TROLLING}

Kling, R. and S. Iacono. 1984. The control of information systems developments after implementation. Communications of the ACM 27(12):1218-1226.

Kling, R. and S. Iacono. 1988. Mobilization of Support for Computerization: The Role of Computerization Movements. Social Problems 35:226.

Milner, R. M. 2013. Hacking the social: Internet memes, identity antagonism, and the logic of lulz. The Fibreculture Journal 22(2013): Trolls and The Negative Space of the Internet.

Phillips, A. 2012. Five Things Academics Might Learn From How the Rowdy Blogosphere Handles Fucknecks. Fembot: Feminism, New Media, Science, and Technology.

Phillips, W. 2011a. A Brief History of Trolls. http://www.dailydot.com/via/phillips-briefhistory-of-trolls/

Phillips, W. 2011b. LOLing at tragedy: Facebook trolls, memorial pages and resistance to grief online. First Monday 16(12).

Phillips, W. 2011c. Meet the trolls. Index On Censorship 40(2):68-76.

Phillips, W. 2015. This is why we can't have nice things: Mapping the relationship between online trolling and mainstream culture. MIT Press.

Postman, L. 1953. Perception, motivation, and behavior. Journal of Personality 22(1):17-31.

Preece, J. 2004. Etiquette online: from nice to necessary. Communications of the ACM 47(4):5661.

Redish, M. H. 1982. The value of free speech. University of Pennsylvania Law Review 130(3):591-645.

Sanfilippo, M. R., Yang, S. and P. Fichman. 2017. Managing online trolling: From deviant to social and political trolls. Hawaii International Conference on Systems Science 50. 


\section{MULTIDIMENSIONALITY OF TROLLING}

Sawyer, S. and K. R. Eschenfelder. 2002. Social informatics: Perspectives, examples, and trends. Annual Review of Information Science and Technology 36(1):427-465.

Schwartz, M. 2008. Malwebolence. New York Times Magazine 24-29.

Shachaf, P. and N. Hara. 2010. Beyond vandalism: Wikipedia trolls. Journal Of Information Science 36(3):357-370.

Shaw, F. (2013). Still 'Searching for Safety Online': collective strategies and discursive resistance to trolling and harassment in a feminist network. The Fibreculture Journal 22(2013): Trolls and The Negative Space of the Internet.

Suler, J. R. and W. L. Phillips. 1998. The bad boys of cyberspace: Deviant behavior in a multimedia chat community. CyberPsychology and Behavior 1(3):275-294.

Turgeman-Goldschmidt, O. 2005. Hackers' accounts: Hacking as a social entertainment. Social Science Computer Review 23(1):8-23.

Utz, S. 2005. Types of deception and underlying motivation: What people think. Social Science Computer Review 23(1):49-56.

Wade, P. 2014. Race, Ethnicity, and Technologies of Belonging. Science, Technology and Human Values, 39(4):587-596.

Whitty, M. T. 2005. The realness of cybercheating: Men's and women's representations of unfaithful internet relationships. Social Science Computer Review 23(1):57-67.

Williams, A., Oliver, C., Aumer, K. and C. Meyers. 2016. Racial microaggressions and perceptions of Internet memes. Computers in Human Behavior 63:424-432.

Wilson, J., Fuller, G. and C. McCrea. 2013. Troll theory? The Fibreculture Journal 22(2013): Trolls and The Negative Space of the Internet. 
MULTIDIMENSIONALITY OF TROLLING

Tables

Table 1. Frequency of codes and percent of co-occurrence of experience per code

\begin{tabular}{|l|r|r|}
\hline Code & Frequency & Co-occurrence with Experience \\
\hline Activism or ideology & 22 & $9 \%$ \\
\hline Anonymity & 19 & $11 \%$ \\
\hline Behavioral tactics & 49 & $10 \%$ \\
\hline Boundary & 6 & $17 \%$ \\
\hline Bullying & 15 & $7 \%$ \\
\hline Communities & 24 & $50 \%$ \\
\hline Cultural aspects & 14 & $14 \%$ \\
\hline Demographics & 15 & $20 \%$ \\
\hline Disinhibition & 8 & $13 \%$ \\
\hline Enabling factor & 16 & $13 \%$ \\
\hline Enjoyment & 37 & $11 \%$ \\
\hline Experience & 29 & $100 \%$ \\
\hline Express opinions & 12 & $8 \%$ \\
\hline Features of online trolling or troll & 25 & $8 \%$ \\
\hline Hacking & 5 & $40 \%$ \\
\hline Identity & 15 & $20 \%$ \\
\hline Impact & 22 & $18 \%$ \\
\hline Intention & 22 & $5 \%$ \\
\hline Intervention and governance & 11 & $18 \%$ \\
\hline Joking or satire & 27 & $11 \%$ \\
\hline Malevolence or abnormal impulse & 2 & $0 \%$ \\
\hline Media & 8 & $13 \%$ \\
\hline Meme & 12 & $0 \%$ \\
\hline Motivation & 26 & $31 \%$ \\
\hline Online and offline & 9 & $11 \%$ \\
\hline Perception and attitude toward & 51 & $22 \%$ \\
\hline Provocation and distraction & 30 & $7 \%$ \\
\hline Psychological factors & 9 & $44 \%$ \\
\hline Reaction & 36 & $17 \%$ \\
\hline Social status & 7 & $38 \%$ \\
\hline Technological features (enabling factor) & 7 & $24 \%$ \\
\hline Troll and trolling & & $4 \%$ \\
\hline Trolling-light & $14 \%$ \\
\hline & & \\
\hline
\end{tabular}

Table 2. Participant consideration of trolling behavioral dimensions and motivations to troll

\begin{tabular}{|l|l|l|}
\hline Category & Concept & \# of Participants $(N=10)$ \\
\hline Behavioral dimensions & Provocative & 10 \\
\hline
\end{tabular}




\begin{tabular}{|l|l|l|}
\hline \multirow{4}{*}{} & Repetition & 10 \\
\cline { 2 - 3 } & Serious opinion & 10 \\
\cline { 2 - 3 } & Intentionality & 9 \\
\hline & Satire & 9 \\
\cline { 2 - 3 } & Pseudo-sincerity & 6 \\
\cline { 2 - 3 } & $\begin{array}{l}\text { Representative of public } \\
\text { opinion }\end{array}$ & 6 \\
\cline { 2 - 3 } & Ratio of interaction & 3 \\
\hline & Target group & 2 \\
\hline Modivations & 0 \\
\cline { 2 - 3 } & Nature of platform & 0 \\
\hline & Enjoyment & 10 \\
\cline { 2 - 3 } & Ideological, political & 9 \\
\cline { 2 - 3 } & Social & 6 \\
\cline { 2 - 3 } & Other & 1 \\
\cline { 2 - 3 } & Psychological & 0 \\
\cline { 2 - 3 } & Technology & 0 \\
\hline
\end{tabular}

Table 3. Defining behavioral dimensions

\begin{tabular}{|c|c|c|}
\hline Concept & Definition & References \\
\hline Meaningfulness & $\begin{array}{l}\text { Communicating serious or social } \\
\text { opinions through behaviors in context. }\end{array}$ & $\begin{array}{l}\text { Hopkinson } 2013 \\
\text { Herring et al. } 2002 \\
\text { Krappitz and Lialina } 2012 \\
\text { Kirman, Lineham and } \\
\text { Lawson } 2012\end{array}$ \\
\hline Representativeness & $\begin{array}{l}\text { Meanings or motivations underlying } \\
\text { behaviors are indicative of public } \\
\text { opinion on serious or social issues. }\end{array}$ & $\begin{array}{l}\text { Fichman and Sanfilippo } \\
2015 \\
\text { Kirman, Lineham and } \\
\text { Lawson } 2012\end{array}$ \\
\hline Pseudo-sincerity & $\begin{array}{l}\text { Actors who provide the impression of } \\
\text { particular motivations or objectives, } \\
\text { while actually driven by opposing or } \\
\text { contradicting motivations or objectives. }\end{array}$ & $\begin{array}{l}\text { Hardaker } 2010 \\
\text { Herring et al. } 2002\end{array}$ \\
\hline Intentionality & $\begin{array}{l}\text { Intentional behaviors are those that are } \\
\text { premeditated and designed to manifest } \\
\text { as they do. }\end{array}$ & $\begin{array}{l}\text { Hardaker } 2010 \\
\text { Shachaf and Hara } 2010\end{array}$ \\
\hline Provocativeness & $\begin{array}{l}\text { A behavioral dimension reflecting an } \\
\text { intention to "disrupt or exacerbate" } \\
\text { and/or a function of "baiting" others } \\
\text { through contention or controversy. }\end{array}$ & $\begin{array}{l}\text { Bishop } 2014 \\
\text { Hardaker } 2010 \\
\text { Herring et al. } 2002 \\
\text { Hopkinson } 2013 \\
\end{array}$ \\
\hline Repetition & Recurring or iterative behaviors. & Shachaf and Hara 2010 \\
\hline Satire & $\begin{array}{l}\text { Actions and behaviors that appear prima } \\
\text { facie to communicate a particular, often }\end{array}$ & $\begin{array}{l}\text { Kirman, Lineham and } \\
\text { Lawson } 2012\end{array}$ \\
\hline
\end{tabular}




\begin{tabular}{|l|l|l|}
\hline & $\begin{array}{l}\text { extreme, perspective, but through } \\
\text { humor, hyperbole, and other rheotircal } \\
\text { devices, truly reflects more nuanced } \\
\text { values and opinions. }\end{array}$ & \\
\hline
\end{tabular}

Table 4. Multidimensional relationships of trolling behaviors

\begin{tabular}{|c|c|c|c|}
\hline & Premise & Conclusion & Relationship \\
\hline 1 & Provocative, Satire & Repetition & Bidirectional \\
\hline 2 & Intentionality, Provocative & $\begin{array}{l}\text { Serious opinions, } \\
\text { Representative of } \\
\text { public opinions, } \\
\text { Repetition }\end{array}$ & Directional \\
\hline 3 & Pseudo-Sincerity & $\begin{array}{l}\text { Serious opinions, } \\
\text { Intentionality, Satire }\end{array}$ & Directional \\
\hline 4 & $\begin{array}{l}\text { Repetition, Intentionality, } \\
\text { Provocative, Satire }\end{array}$ & $\begin{array}{l}\text { Serious opinions, } \\
\text { Representative of } \\
\text { public opinions, } \\
\text { Pseudo-sincerity }\end{array}$ & Directional \\
\hline 5 & Representative of public opinion & $\begin{array}{l}\text { Serious opinions, } \\
\text { Provocative }\end{array}$ & Bidirectional \\
\hline 6 & Serious opinions, Satire & $\begin{array}{l}\text { Pseudo-sincerity, } \\
\text { Intentionality }\end{array}$ & Directional \\
\hline 7 & Serious opinions, Intentionality & Pseudo-sincerity, Satire & Directional \\
\hline 8 & $\begin{array}{l}\text { Serious opinions, Repetition, } \\
\text { Provocative, Satire }\end{array}$ & $\begin{array}{l}\text { Representative of } \\
\text { public opinion, Pseudo- } \\
\text { sincerity, Intentionality }\end{array}$ & Directional \\
\hline 9 & $\begin{array}{l}\text { Serious opinions, Repetition, } \\
\text { Pseudo-sincerity, Intentionality, } \\
\text { Provocative, Satire }\end{array}$ & $\begin{array}{l}\text { Representative of } \\
\text { public opinion }\end{array}$ & Directional \\
\hline 10 & $\begin{array}{l}\text { Serious opinions, Representative of } \\
\text { public opinions, Pseudo-sincerity, } \\
\text { Intentionality }\end{array}$ & Repetition & Directional \\
\hline 11 & $\begin{array}{l}\text { Serious opinions, Representative of } \\
\text { public opinions, Repetition, } \\
\text { Provocative, Satire }\end{array}$ & $\begin{array}{l}\text { Pseudo-sincerity, } \\
\text { intentionality }\end{array}$ & Directional \\
\hline
\end{tabular}

\section{Figures}

Figure 1. Relationships between behavioral types and behavioral dimensions (trolling and nontrolling) 


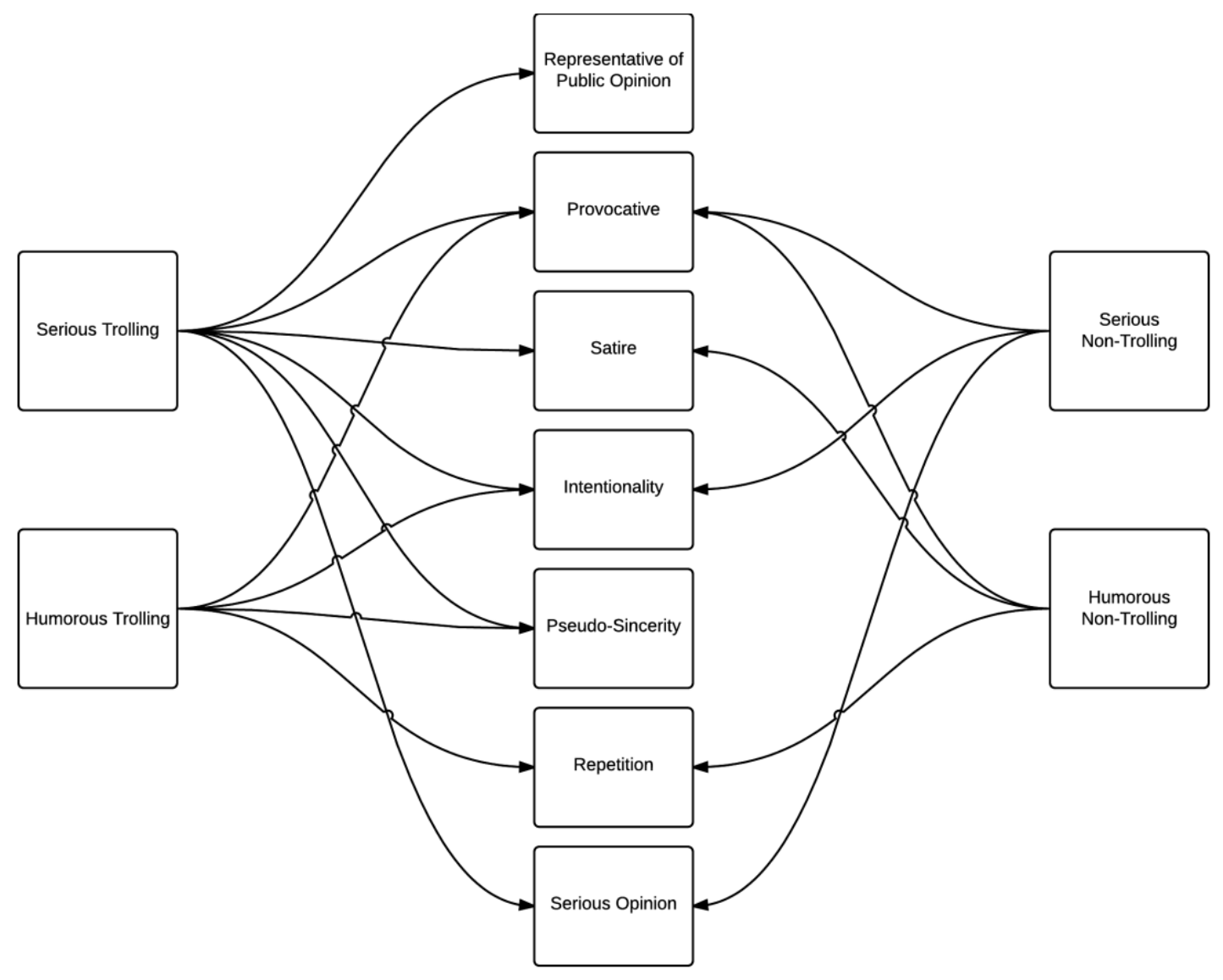

Figure 2. Behaviors experienced by roles

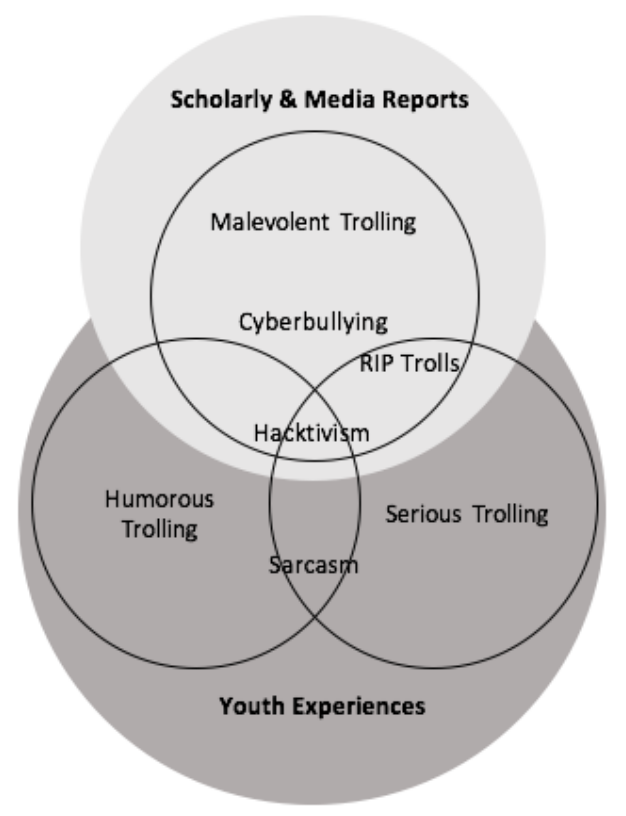


Figure 3. Typology of trolling by humor and social inclusivity

Anti-social

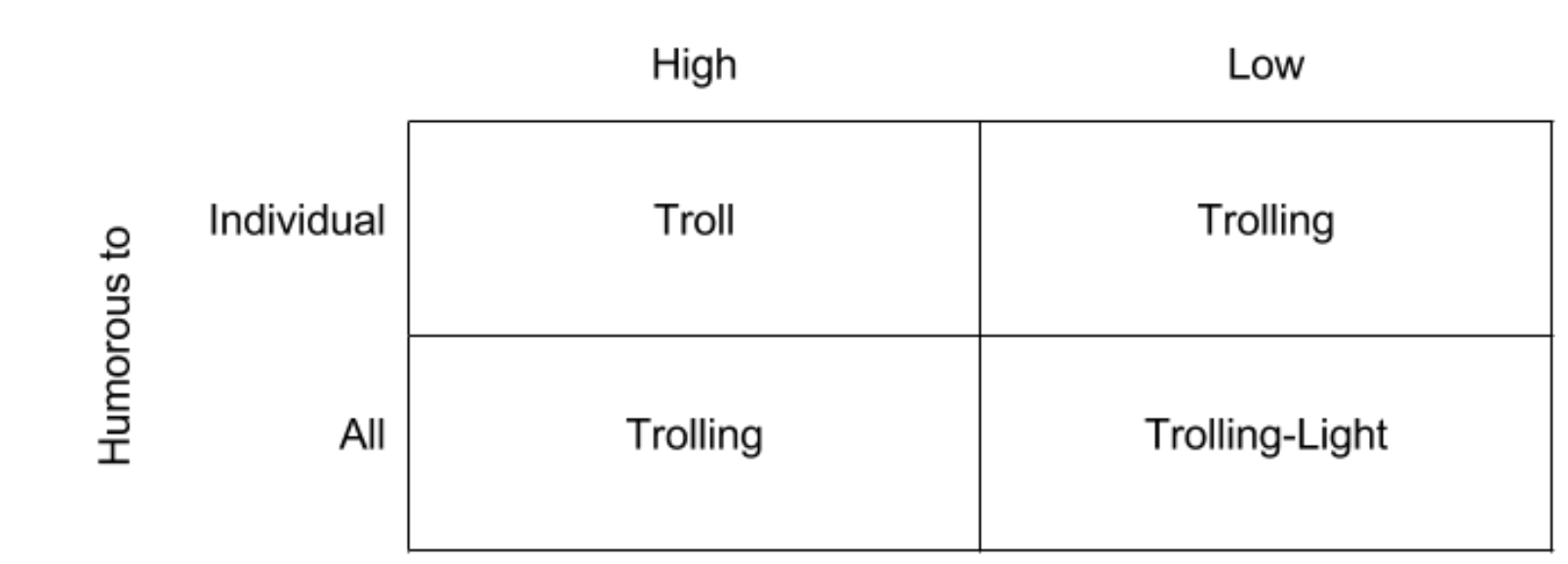

\section{Appendix}

Table 5. Codebook

\begin{tabular}{|l|l|}
\hline CODE & \multicolumn{1}{|c|}{ DEFINITION } \\
\hline Activism or ideology & $\begin{array}{l}\text { Activism or ideology (including social, religious, or } \\
\text { political) as pertains to motivations for trolling. This } \\
\text { includes desires for: 1) community and social change for } \\
\text { civil rights, 2) political changes, 3) technology as a savior } \\
\text { or technological utopianism, and 4) civil liberties. } \\
\text { Hacktivism and political trolling are strongly associated } \\
\text { with these motivations. }\end{array}$ \\
\hline Anonymity & $\begin{array}{l}\text { The role of anonymity in online and mediated environments } \\
\text { as encourages and enables trolling. This includes } \\
\text { dissociation between identify and online behaviors. }\end{array}$ \\
\hline Behavioral tactics & $\begin{array}{l}\text { Behaviors, mechanisms, tropes, and tactics that do and do } \\
\text { not comprise trolling. }\end{array}$ \\
\hline Boundary & $\begin{array}{l}\text { Boundary of behaviors, including boundary spanning, } \\
\text { boundary pushing, whether certain behavior across the } \\
\text { boundary }\end{array}$ \\
\hline
\end{tabular}




\begin{tabular}{|c|c|}
\hline CODE & DEFINITION \\
\hline Bullying & $\begin{array}{l}\text { Cyber bullying behaviors and the relationships between } \\
\text { bullying and trolling. }\end{array}$ \\
\hline Communities & $\begin{array}{l}\text { How particular communities are impacted by trolling, } \\
\text { encourage trolling, manage behaviors, are impacted by } \\
\text { trolling, or support trolls. }\end{array}$ \\
\hline Cultural aspects & $\begin{array}{l}\text { Social and cultural dimensions of online communities as } \\
\text { they enable particular online behaviors, including trolling, } \\
\text { such as norms surrounding debate, reform, boundary } \\
\text { pushing or spanning, and conformity. }\end{array}$ \\
\hline Demographics & $\begin{array}{l}\text { Who participates in trolling behaviors and the } \\
\text { characteristics of populations of trolls. }\end{array}$ \\
\hline Disinhibition & $\begin{array}{l}\text { Online disinhibition as an enabling factor for trolling or } \\
\text { discussion of the dimensions of online disinhibition effects } \\
\text { as contributing to online behaviors. Online disinhibition can } \\
\text { be understood as the lowering of behavioral inhibitions in } \\
\text { technologically mediated, dispersed, and anonymous } \\
\text { interactions between individuals without offline } \\
\text { relationships due to the reduced possibility of consequences } \\
\text { and dissociation of self from actions. }\end{array}$ \\
\hline Enabling factor & Factors that enable online trolling. \\
\hline Enjoyment & $\begin{array}{l}\text { How seeking enjoyment may motivate trolls, as well as } \\
\text { discussion of who might enjoy or find humor in particular } \\
\text { behaviors. }\end{array}$ \\
\hline Experience & $\begin{array}{l}\text { Particular experiences trolling, being trolled, or interacting } \\
\text { with communities around trolls. }\end{array}$ \\
\hline Express opinions & $\begin{array}{l}\text { Whether a certain behavior is to make a point of view or } \\
\text { declare one's position, and the differentiation between } \\
\text { making a point and trolling }\end{array}$ \\
\hline $\begin{array}{l}\text { Features of online trolling or } \\
\text { troll }\end{array}$ & $\begin{array}{l}\text { Characteristics and features that are used to identify trolling } \\
\text { (or trolls) or not. }\end{array}$ \\
\hline Hacking & $\begin{array}{l}\text { Hacking behaviors and the relationships between hacking } \\
\text { and trolling. }\end{array}$ \\
\hline Identity & $\begin{array}{l}\text { How identity formation and presentation impacts trolling } \\
\text { behaviors and their perception, reaction to, and impact. }\end{array}$ \\
\hline Impact & $\begin{array}{l}\text { How particular online behaviors impact communities or } \\
\text { society. }\end{array}$ \\
\hline Intention & $\begin{array}{l}\text { Whereas motivations include psychological, emotional, and } \\
\text { outcome-oriented objectives, intentions are applied to } \\
\text { discussions of what trolls seek to achieve and what the } \\
\text { desired outcomes of trolling are. }\end{array}$ \\
\hline Intervention and Governance & $\begin{array}{l}\text { How to deal with the results of certain deviant behaviors, } \\
\text { including: who takes the responsibility, whether or not to } \\
\text { interfere, how to react. }\end{array}$ \\
\hline
\end{tabular}




\begin{tabular}{|l|l|}
\hline CODE & \multicolumn{1}{|c|}{ DEFINITION } \\
\hline Joking or satire & $\begin{array}{l}\text { Identification of particular behaviors as joking or satire, as } \\
\text { well as discussion about how these behaviors relate to } \\
\text { trolling. }\end{array}$ \\
\hline $\begin{array}{l}\text { Malevolence or abnormal } \\
\text { impulse }\end{array}$ & $\begin{array}{l}\text { Malevolence or abnormal impulses as motivations for } \\
\text { deviant or anti-social behaviors associated with trolling, } \\
\text { including both sociological aspects and experiences of } \\
\text { individuals. }\end{array}$ \\
\hline Media & $\begin{array}{l}\text { How the media treats the concept of trolling, represents or } \\
\text { constructs trolling, or provides narratives about online } \\
\text { behaviors, in contrast to scholars or the general public. This } \\
\text { may include discussion of why they represent content in a } \\
\text { particular or what the impact of their narrative is. }\end{array}$ \\
\hline Meme & Memes as content shared in a viral pattern. \\
\hline Motivation & Possible motivations for online trolling. \\
\hline Online and offline & $\begin{array}{l}\text { Differentiation and comparisons between online trolling and } \\
\text { different offline behaviors, or online trolling's impact on } \\
\text { offline lives }\end{array}$ \\
\hline Perception and Attitude toward & $\begin{array}{l}\text { How individuals, groups, or society perceive online } \\
\text { behaviors. }\end{array}$ \\
\hline Provocation and Distraction & $\begin{array}{l}\text { Troll's behaviors or intentions as degrading, provoking, } \\
\text { detracting and using swear words. }\end{array}$ \\
\hline Psychological Factors & $\begin{array}{l}\text { Psychological factors that contribute to trolling behaviors, } \\
\text { as motivations for both rational and irrational behaviors. }\end{array}$ \\
\hline Reaction & $\begin{array}{l}\text { How individuals, groups, or society react to particular } \\
\text { behaviors. }\end{array}$ \\
\hline Social status & $\begin{array}{l}\text { Social status negotiation as motivates trolling to either } \\
\text { develop a sense of belonging within a community or seek } \\
\text { attention or social capital. Social status includes all } \\
\text { attributes of status, such as power, relationships, and } \\
\text { influence. }\end{array}$ \\
\hline Tronabling factor) & $\begin{array}{l}\text { Technical features of online communities or particular } \\
\text { platforms that enable trolling behaviors, such as } \\
\text { asynchronous interactions, variation in persistence of } \\
\text { identity, barriers to participation, and richness of media } \\
\text { supporting interaction. }\end{array}$ \\
\hline Trolling-light & $\begin{array}{l}\text { What a troll or trolling is or isn't. } \\
\text { Trolling-light, as a more humorous and accessible form of } \\
\text { trolling. }\end{array}$ \\
\hline &
\end{tabular}

